\title{
THE NON-ANTIGENICITY OF INTACT OVA OF CLONORCHIS SINENSIS
}

\author{
T. SuN \\ Department of Pathology, University of Hong Kong
}

\section{Plate XXVIII}

IMMUNODIFFUSION studies indicate that ova of Clonorchis sinensis do not act as effective antigen in mammalian infection (Sun and Gibson, 1969). However, it is intact and not broken ova that are usually present in the bile of the definitive host, and a study on the antigenicity of the intact ova might therefore give results more comparable to those in the natural condition. In this paper, the circum-oval precipitin test and the implantation of intact ova were used for the investigation of the humoral and cellular reactions to clonorchis ova (see also Sun, 1967).

\section{MATERIAL AND METHODS}

Circum-oval precipitin tests. Clonorchis ova obtained from faeces and bile of patients and of experimentally infected rabbits were concentrated by the method of Mueller (1959), thoroughly washed in saline and used intact. Antisera from 100 human cases of clonorchiasis and from 10 experimentally infected rabbits were used, and also sera from 10 rabbits artificially immunised with extracts of lyophilised ova as described by Sun and Gibson. All sera were known to contain precipitins against clonorchis antigens. The procedure was that of Oliver-González (1954). Each test was controlled by the simultaneous exposure of eggs to the appropriate normal serum.

Ectopic ova in human tissues. In necropsy material collected from 1961 to 1966, 509 cases were reviewed in which flukes or ova were identified in the histological sections studied by routine methods. Sixteen biopsies containing adult Clonorchis or its ova were also reviewed.

Experimental implantation of ova. Seventy-two mice of either sex weighing 25-30 g were used. Half were given a subcutaneous injection of 500 ova in $0.5 \mathrm{ml}$ Ringer's solution. The other 36 were given $0.5 \mathrm{ml}$ of normal rabbit bile in the same way. Injection sites were marked on the skin with red indelible ink. The ova were obtained by incubation of batches of 40 flukes in $6 \mathrm{ml}$ sterile Ringer's solution for $12 \mathrm{hr}$. The flukes were then removed and the concentration of the eggs that had been passed into the medium was adjusted to $1000 \mathrm{per} \mathrm{ml}$ by counting under a microscope and dilution. From each group, 2 mice were killed $5 \mathrm{hr}$ after injection and then 2 per day up till the 12th day; another 3 mice from each group were killed on the 8th, 15th, 22nd and 29th days. At necropsy, the skin and subcutaneous tissue at the marked site of injection, the regional lymph-nodes and the spleen were excised and fixed in 4 per cent. formaldehyde, embedded in paraffin wax and sectioned. Sections were cut at numerous levels through the skin blocks so that the injection site was fully examined.

\section{RESULTS \\ Circum-oval precipitin tests}

No precipitate formed around the ova when they were exposed to clonorchiasis antisera either of human or of rabbit origin, or to control normal rabbit or human serum. The tests with anti-clonorchis-ovum rabbit sera were also negative: as these 10 sera prepared against extracts of lyophilised ova were known to contain precipitins against egg antigens (Sun and Gibson), it was concluded that these antigens do not escape through the egg-shell.

\section{Reactions to ectopic ova in human tissues}

The observations were confined to instances where ova lay free outside the bodies of flukes and within the host tissues. Ova that lay free in the bile ducts and were not associated 


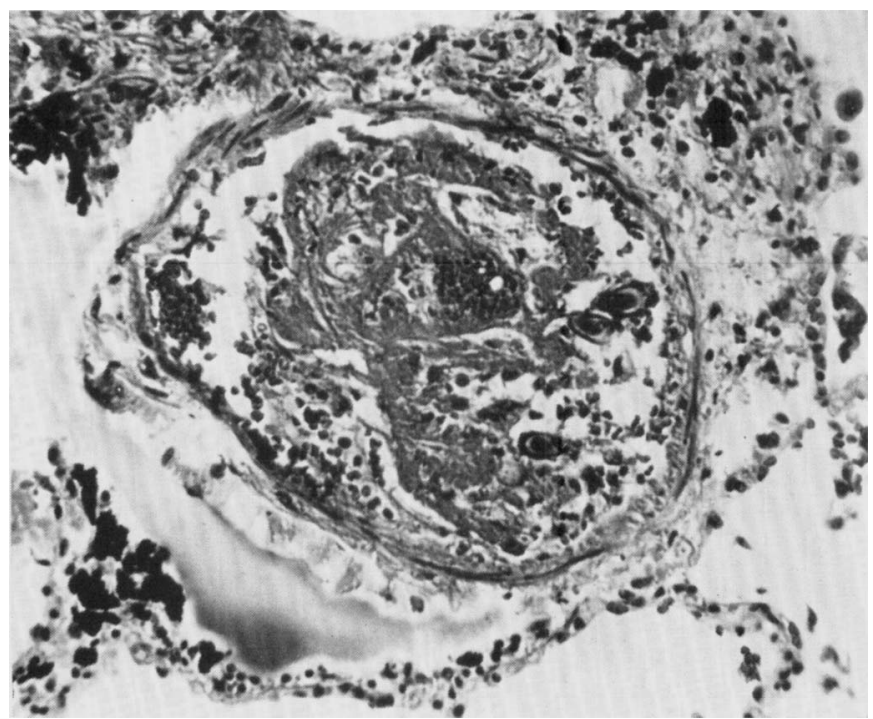

FIG. 1.-Clonorchis ova entangled in embolus in pulmonary artery in a case of pyogenic cholangitis and cholangiocarcinoma. Haematoxylin and eosin. $\times 210$.

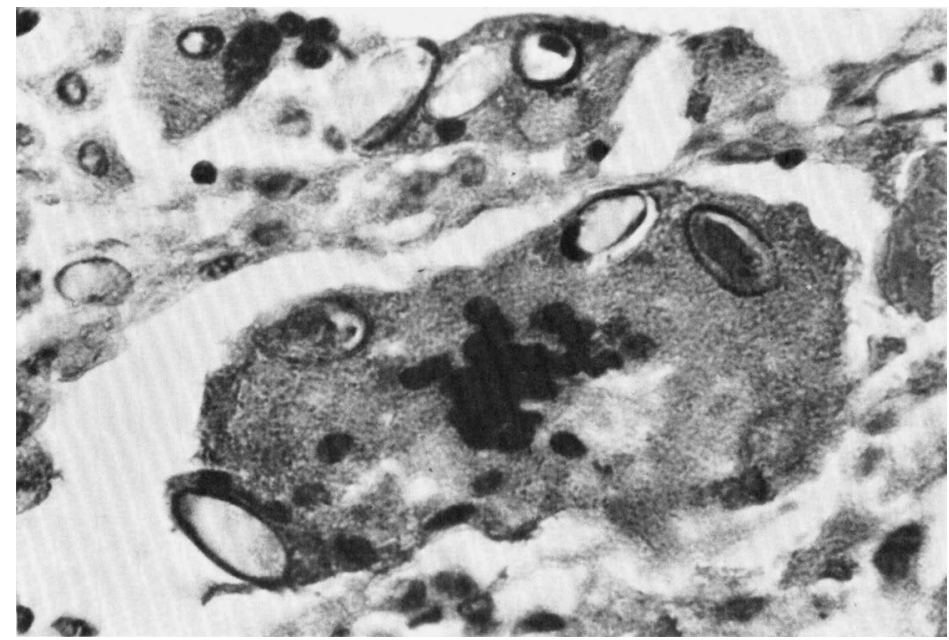

FIG. 2.-Clonorchis ova engulfed by a giant cell in the wall of an inflamed gall bladder in a case of recurrent pyogenic cholangitis; histiocytes with foamy and eosinophilic cytoplasm are also present. HE. $\times 510$. 
with any cellular response, and ova occasionally detected as a nidus of an intrahepatic calculus (Teoh, 1963) were disregarded. Among all the 509 necropsy and 16 biopsy cases there were only four in which clonorchis ova lay in the tissues outside the bile ducts. All were cases of pyogenic cholangitis and two were complicated by cholangiocarcinoma. In one case the ova were incorporated in emboli impacted in pulmonary artery branches (fig. 1). In two others the ova were buried deeply in the wall of the gall-bladder and in the fourth they lay within the tissues of the liver. The tissue reactions in the three latter cases were all dominated by acute inflammatory elements of the bacterial infection, but large histiocytes with foamy and eosinophilic cytoplasm and giant cells were also present and some had engulfed eggs and cholesterol crystals (fig. 2). Polymorphs, lymphocytes and plasma cells were present and eosinophils were seen in the gall-bladder lesions, but not in the liver lesion. No defined granulomas comparable to those seen in schistosomiasis were found in any of the cases.

\section{Experimental implantation of ova}

A cellular reaction to the eggs appeared first one day after injection and increased in intensity thereafter. It consisted chiefly of polymorphs; a few lymphocytes and eosinophils appeared later. Ova disappeared from the injection site 5 days after injection, and the cellular reaction subsided gradually. Giant cells, epithelioid cells or histiocytes similar to those in the human lesions of clonorchiasis were not seen at any time. Eggs could not be traced in the regional lymph-nodes or in the spleen. In the mice given an injection of bile, a leucocytic infiltration appeared on the day of injection and the inflammatory reaction was more marked than in the "egg group". In the first few days the cellular exudate was the same as that in the "egg group", but giant cells and foamy histiocytes began to make their appearance 10 days after injection. Fibrocytes became evident at the same time. The inflammatory reaction subsided gradually after the 3rd wk.

\section{Discussion}

The reaction of host sera in the circum-oval precipitin test to the ova of Trichosomoides crassicauda, Schistosoma mansoni and Nippostrongylus muris is due to antigen in secretions from the ova (Smith, 1946; Oliver-González, 1954; Jackson, 1960). The egg-shell of Ascaris has been proved to be inert, but the embryo it contains is antigenic: the tissue reaction caused by the eggs in experimental implantation is most marked at the larval or hatching stage (Nakamura, 1960), and is probably due to the release of metabolic products or secretions of the ovum (Fung and Sun, 1963), which then become available as antigen. The circum-oval reaction then appears if the embryo secretes sufficient antigen to cause an antibody response and if the egg-shell is permeable. Schistosome ova fulfil these conditions; the ova of Clonorchis do not. Schistosome miracidia hatch out in water and presumably require their own enzymes to rupture the shell, but clonorchis miracidia hatch out only when the ovum has been ingested by a molluscan host and do not appear to depend on their own secretions for the purpose. Thus little if any secretion that may act as antigen is associated with the clonorchis ovum. The egg-shells of $S$. mansoni and S. japonicum are found on electron microscopy to be composed of a single layer which includes a system of fine tubules, caverns or capillaries (Inatomi, 1962). The tubules open internally and externally so that contents of the ovum can permeate to the outside. The egg-shell of Clonorchis is composed of a thin outer layer and a thick inner layer as well; a tubular system does not develop in either layer (Inatomi). These recent electron-microscope findings are at variance with an older report of the permeability of the clonorchis ovum (Faust and Khaw, 1927) and indicate how antigens of the embryo fail to reach the surface of the ovum and react in the circum-oval test.

Clonorchis ova have been observed outside the biliary passages only in the presence of pyogenic cholangitis. Although the event is rare, ova may reach the pulmonary artery in the emboli that sometimes complicate recurrent pyogenic cholangitis (Lai, McFadzean and Yeung, 1968). In ectopic parasitism of $A$. lumbricoides, eggs of a worm lodged in the liver may also be carried to the lungs (Fung and Sun). Otherwise clonorchis ova have been found only in or around the biliary passages and any reaction they may induce there is complicated 
by the existence of suppuration and the extravasation of bile. Granulomas closely comparable to those of schistosomiasis were not found either in the human or in the experimental material. The experimental results indicate that the giant cells and histiocytes that appear around the ova and may even engulf them are formed in response to the presence of bile. The schistosome granuloma on the other hand is probably an immune response to egg antigens (Andrade, Paronetto and Popper, 1961; v. Lichtenberg, 1964) and egg antigen and fixed host globulin have been detected around the ova in the granulomas (v. Lichtenberg, Smith and Cheever, 1966). Ascaridic granuloma is apparently also dependent on immunological factors, for it is slow to develop in newborn mice (v. Lichtenberg and Mekbel, 1962) and is accelerated and enhanced in sensitised adult mice (Mekbel and v. Lichtenberg, 1962).

\section{SUMMARY}

The failure of clonorchis ova to elicit antibody in infections is not due simply to the rarity with which ova enter the tissues. The ovum does not provoke granuloma formation as some other ova do when it is injected experimentally into the subcutaneous tissue of mice in the absence of bile. Granulomatous appearances in occasional human lesions in which ova are found in the tissues outside the biliary tree are due to the presence of bile. The circum-oval precipitin test is consistently negative and the shell of the clonorchis ovum is impermeable to the antigens in the embryo. It is concluded that clonorchis ova play no important role in stimulating humoral and cellular immunity in the definitive host.

This work was supported by grant AFOSR 683-64 from the United States Air Force Office of Scientific Research to Professor J. B. Gibson. The author also wishes to thank Miss H. W. Ma and Mr Y. M. Leung for technical assistance.

\section{REFERENCES}

Andrade, Z. A., Paronetto, F., And 1961. Amer. J. Path., 39, 589. POPPER, $\mathrm{H}$.

FaUST, E. C., AND KhaW, O. K.

1927. Studies on Clonorchis sinensis (Cobbold), (Amer. J. Hyg. Monogr. Ser., no. 8), Baltimore.

Fung, P. C., And Sun, T. 1963. Zhong. Yixue Z., 49, 54 (in Chinese). INATOMI, S. ․ . - . . 1962. Okayama Igakkai Zasshi, 74, 31 (in Japanese with English summary).

JACKSON, G. J. . $\quad$. $\quad$. $\quad$. $\quad$. 1960. J. Infect. Dis., 106, 20.

LaI, K. S., McFadzean, A. J. S., AND 1968. Br. Med.J., 1, 22. YeUNG, R.

V. LICHTENBERG, F. . . . . . .

1964. Amer. J. Path., 45, 75.

v. Lichtenberg, F., ANd Mekbel, S. . 1962. J. Infect. Dis., 110, 246.

v. Lichtenberg, F., Smith, J. H., ANd 1966. Amer.J. Trop. Med. Hyg., 15, 886.

CheEVER, A. W.

Mekbel, S., AND v. Lichtenberg, F. 1962. J. Infect. Dis., 110, 253.

Mueller, J. F. . . . . . 1959. J. Parasit., 45, 353.

Nakamura, F. . . . . . . 1960. Kiseichugaku Zasshi, 9, 88 (in Japanese).

Oliver-GonZÁlez, J. . . . 1954. J. Infect. Dis., 95, 86.

SMITH, V. S. $\quad . \quad$. $\quad$. $\quad$. 1946. J. Parasit., 32, 136.

Sun, T. $\quad . \quad$. $\quad . \quad$. $\quad$. 1967. M.Sc. Thesis, Univ. Hong Kong.

Sun, T. And Gibson, J. B. . 1969. Amer. J. Trop. Med. Hyg., 18, 241.

Tеон, T. B. $\quad$. $\quad$. $\quad$. $\quad$. $\quad$. 1963. J. Path. Bact., 86, 123. 